\title{
Effect of sea turtle rehabilitation centres in Queensland, Australia, on people's perceptions of conservation
}

\author{
Alexandra D. Feck ${ }^{1, *}$, Mark Hamann ${ }^{2}$ \\ ${ }^{1}$ School of Marine and Tropical Biology, and ${ }^{2}$ School of Earth and Environmental Science, James Cook University, \\ Townsville, Queensland 4811, Australia
}

\begin{abstract}
Sea turtles are found worldwide, with all 7 species considered species of conservation concern. The public has seen sea turtle rehabilitation centres as an important tool for conserving sea turtle populations. However, educating the public regarding threats to sea turtles and how they can minimise these threats by making a change in their own lives may be more beneficial than rehabilitation alone, in terms of the ability to restore turtle numbers. In order to determine the educational role of rehabilitation centres, 245 surveys were distributed at several Australianbased rehabilitation centres. The survey was in 2 parts. The first part collected information about visitor's knowledge of threats, their willingness to pay for conservation, and socio-economic information. The second part determined what threats visitors had learned about, whether visitors would make a change to help support sea turtle conservation, and whether they would be willing to pay more for conservation following their visit. Overall, results showed that all visitors to the sea turtle rehabilitation centres were willing to make a change in their lives to help protect sea turtles. Additionally, the majority of visitors were willing to donate annually to sea turtle conservation. The extra revenue raised could be used for conservation purposes and further research to address the threats sea turtles face. Combining the opportunity for visitors to observe sea turtles up close and learn about threats and how they can be minimised at rehabilitation centres will assist in increasing population sizes and protecting them into the future.
\end{abstract}

KEY WORDS: Rehabilitation · Sea turtles · Education $\cdot$ Conservation $\cdot$ Threats $\cdot$ Willingness-to-pay Resale or republication not permitted without written consent of the publisher

\section{INTRODUCTION}

Sea turtles are found in all ocean regions of the world, with the exception of polar regions, and all species are listed by the International Union for the Conservation of Nature (IUCN) as species of conservation concern, with the exception of the flatback turtle (which is listed as Data Deficient). Pressures on sea turtles vary within and between species and populations. Threats are mainly attributed to anthropogenic sources, for example, commercial consumption, fisheries bycatch, boat strike, coastal development leading to habitat change, light pollution, ingestion of wastes such as plastics or other pollutants, and entanglement in fishing equipment or other debris (Hutchinson \& Simmonds 1992, Tisdell \& Wilson 2002b, Mrosovsky et al. 2009, Casale et al. 2010). While these impacts vary across temporal and spatial scales, most populations have experienced some degree of human-related impact (Wallace et al. 2010, 2011).

Sea turtle conservation is important for a variety of reasons, such as to protect their ecological, aesthetic, economic, existence, and bequest values (Tisdell \& Wilson 2001). Consequently, the governments of many nations have developed recovery or manage- 
ment plans for their conservation (e.g. Australia; SEQPaC 2003). Generally speaking these plans put into place various methods to help protect sea turtles from decline and to support efforts to increase their long-term survival (SEQPaC 2003). In some cases they prescribe specific actions that can be, or are, linked to legislative change, such as speed limits to minimise the risk of boat strikes (SEQPaC 2003, Hazel et al. 2007), or implementation of bycatch reduction measures or measures to reduce commercial use. However, increasingly sea turtles are being seen as flagship species for conservation (Tisdell \& Wilson 2003), and, consequently, community-based conservation efforts are increasing as seen in the establishment of sea turtle rehabilitation centres.

Sea turtle rehabilitation centres operate throughout Australia to help with the conservation of sea turtle populations. Hundreds of sea turtles are brought to sea turtle hospitals each year and treated for a variety of illnesses or injuries (Greenland \& Limpus 2003). The majority of animals end up in rehabilitation centres due to anthropogenic impacts such as recovering from injuries from boat strikes or entanglement in nets (Greenland \& Limpus 2003). Depending on the severity of the problem, rehabilitation of sea turtles can take anywhere between a few months and several years before they can be released (Cardona et al. 2012), with an average time of 7 to 8 mo (Greenland \& Limpus 2003). Despite extensive care, some individuals are deemed not suitable for release and if not euthanised are often placed in permanent homes in zoos or aquariums (Cardona et al. 2012). In most cases, rehabilitation centres adopt a triage approach, and take only animals veterinary clinicians believe to have a reasonable chance of rehabilitation and release (Meredith \& Keeble 2011).

The number of successful cases of rehabilitation and release of sea turtles each year is very small in relation to the size of the entire population. For example, in Queensland, the 5 rehabilitation centres release around 50 turtles $\mathrm{yr}^{-1}$ back into the wild from a population that numbers over a million (Chaloupka \& Limpus 2001). It is therefore unlikely that these centres help sea turtle populations increase significantly by rehabilitating sick or injured individuals alone. Additionally, there is little knowledge about whether rehabilitated sea turtles successfully readapt, specifically individuals that have required long and complicated veterinarian treatment (Cardona et al. 2012). Thus, in addition to saving individuals that would otherwise have died, these centres may play a larger role through environmental education and public awareness, although this role is not well documented.
The costs of sea turtle rehabilitation are high given the time, facility, staff, and finance commitments needed to care for an individual sea turtle. While the exact cost per animal has not been published, it is likely to vary considerably between centres and across individuals and could be on the order of several thousand Australian dollars per turtle. Most rehabilitation facilities rely on support from public donations, philanthropic trusts, or corporations, while some receive regular or periodic government funding and/or charge entrance fees for visitors to observe the animals. Although it is costly for turtles to be rehabilitated, it remains an important part of conservation as it can serve as a tool to educate the public about threats to sea turtle survival.

From an educational perspective, 1000s of people visit rehabilitation centres each year worldwide in order to see wild animals 'up close.' The majority of the centres, especially in Australia, seek to educate visitors about the causes of sea turtle injuries/illness and what people can do in their everyday lives to help protect them. Visitors may respond to viewing injured wildlife up close, and thus be willing to change their behaviour to protect sea turtles and/or donate money for their conservation, which has been found to be true for visitors at sea turtle nesting beaches (Tisdell \& Wilson 2001, 2002a, Ballantyne et al. 2007b). This additional revenue can be used for conservation purposes to address management of the threats that sea turtles face, as well as further research into threat mitigation (Wilson \& Tisdell 2000). The tourism economic value of sea turtles and rehabilitation centres can also lead towards legal support to minimise threats, such as enforcing 'go slow zones' and marine littering (Wilson \& Tisdell 2000). Studies have shown that conservation learning, along with observing wildlife up close, is more effective at changing visitors' attitudes towards conservation than is the provision of information about conservation alone (Tisdell \& Wilson 2005b, Ballantyne et al. 2007b).

Therefore, it is likely that visitors that are able to view sea turtles up close at rehabilitation centres, and learn about threats, will become more aware and conservation minded. This change in visitor perceptions may have a greater impact on helping sea turtle populations recover than rehabilitation alone. The purpose of this study is to determine whether observing sea turtles in captivity alters people's perceptions about sea turtle conservation. Specifically, we wanted to know whether visitors that visit sea turtle rehabilitation centres are more likely to adopt a behavioural change in their lives to help protect sea turtles and/or 
donate money to sea turtle conservation. The bulk of past research has been focussed on tourists visiting sea turtle nesting beaches or volunteers (Campbell \& Smith 2005, 2006, Tisdell \& Wilson 2001, 2005a,b, Gray \& Campbell 2007); however, previous studies have not looked at the educational and economic value of sea turtle rehabilitation centres.

\section{METHODS}

In order to determine the educational, economic, and conservation values of sea turtle rehabilitation centres, a detailed questionnaire was developed (in the supplement at www.int-res.com/articles/suppl/ n020p153_supp.pdf). The survey was divided into 2 main sections. Part I of the survey was to obtain background information on the visitors' visit to the facility to determine how conservation minded visitors are, their knowledge about threats to sea turtle survival, how much visitors would be willing to pay for sea turtle conservation, as well as socioeconomic data. Part II of the survey was to determine how educational the visit was in informing visitors about threats sea turtle face and to determine if visitors were willing to make any change in their everyday lives to help minimise threats to sea turtles. Willingness to pay questions were asked again to determine whether visitors would pay more, less, or the same after visiting the facility; amounts stated are in Australian dollars (AUD). Surveying was carried out during September and October 2011, which was a period of economic depression in Queensland following cyclone Yasi and the flooding of Brisbane, Bundaberg, Rockhampton, and many of the surrounding areas. Many of the questions were based on a 5 point Likert scale, ranging from 1 (strongly disagree), 2 (disagree), 3 (neutral), 4 (agree), and 5 (strongly agree). All analysis was done using SPlus 8.0, and a non-parametric Kruskal-Wallis test (K-W test) was used to determine whether there was a statistically significant association between the categorical responses provided for the different survey questions. Data transformations were attempted; however, the data distribution still did not meet the assumptions of a parametric test.

Surveying occurred at Reef $\mathrm{HQ}$, Australia Zoo, Underwater World, and the Cairns Sea Turtle Rehabilitation Centre (CSTRC), and only adults were asked to participate in the surveys. Reef $\mathrm{HQ}$ is a coral reef aquarium with a morning and afternoon tour of the sea turtle hospital, which visitors can only view on a guided tour. Of the total visitors that go on the turtle hospital tour each day, $64 \%$ of visitors go on the morning tour and $36 \%$ of visitors go on the afternoon tour. Visitors heard a talk about threats to sea turtles before they were taken on a tour of the hospital. Additional information about the reason individual sea turtles were in the hospital was explained during the tour. Visitors to the aquarium were approached from between $2 \mathrm{~h}$ and $10 \mathrm{~min}$ before the tour began, in order to give them time to complete the first part of the survey before the talk was given. Around $75 \%$ of the visitors that were planning to visit the sea turtle hospital arrived early enough to be surveyed. In addition, on average, $25 \%$ of those visitors were under 18 yr of age, and were not surveyed. Of the remaining visitors that met the criteria to be surveyed, all of them were asked to participate; $33 \%$ of visitors on the morning tour were willing to complete the survey and $49 \%$ of visitors on the afternoon tour were surveyed. Also some couples were only willing to fill out 1 survey between them, especially older couples ( $>65 \mathrm{yr}$ old). Surveying occurred during the school holidays because a larger number of visitors come to the aquarium during this period.

The CSTRC is not generally open to the public, though some tours are given to school groups. The facility is solely a sea turtle rehabilitation centre; therefore, all visitors have specifically come to see the facility and sea turtles. No admission is charged to view the facility and no talk is given beforehand, but at each turtle, information is given regarding what the turtle is suffering from. Surveying occurred over $1 \mathrm{~d}$ when a tour group was scheduled to visit, and all visitors that were taken on this tour of the centre were surveyed.

The Australia Zoo offers a 'sneak peek' tour of their wildlife hospital for an additional cost. The sneak peek tour allows visitors to see a part of the operating area, as well as the koala recovery area. Sea turtles were not visible; however, there was visual information about threats to sea turtle survival available for visitors to read. Visitors that spent time reading and looking over this information were asked to complete the second part of the survey. Of the total number of visitors that took a tour of the wildlife hospital, only around $30 \%$ read the information about sea turtles. All the visitors that read the information were surveyed. The first part of the survey was not used, as it was too long for visitors to fill out before they entered the centre. Furthermore, there was no way to determine whether visitors would read the information about sea turtles before 
they entered the facility. Surveying occurred over $2 \mathrm{~d}$ in the afternoon during the school holidays because the majority of visitors visit the wildlife hospital after they finish visiting the zoo before they go home.

Underwater World is primarily an aquarium though they also offer a behind the scenes tour 3 times a day for an additional cost, which allows visitors to view the sea turtles in rehabilitation; however, only a maximum of 10 guests can be accommodated on each tour. Due to logistical constraints, visitors were only surveyed after the tour, and some willingness to pay questions had to be removed from the second part. All visitors, excluding children, were asked after the tour if they would be willing to take the survey; however, only approximately $40 \%$ of the visitors were willing. Threats were talked about generally on the tour depending on the individual sea turtles they had in care. Surveying occurred over $3 \mathrm{~d}$ during the school holidays.

\section{RESULTS}

At Reef HQ, 166 Part I surveys were collected and 134 Part II surveys were collected because some visitors did not return to the aquarium after the tour. At the CSTRC, 16 Part I surveys were collected and 17 Part II surveys, because the tour had been given to 1 person already before surveying began, so only Part II was used for that visitor. At Australia Zoo, 43 Part II surveys were collected, and 20 modified Part II surveys were collected at Underwater World.

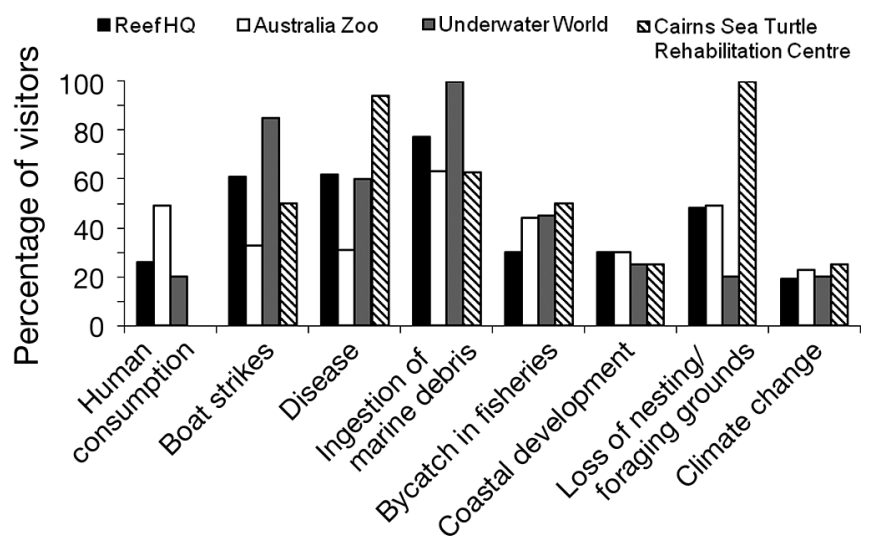

Threats to sea turtle survival

Fig. 1. Survey results: during their visit, visitors to Reef $H Q$ $(\mathrm{N}=143)$, Australia Zoo $(\mathrm{N}=41)$, Underwater World $(\mathrm{N}=$ $20)$, and the Cairns Sea Turtle Rehabilitation Centre $(\mathrm{N}=18)$ learned about a range of threats to sea turtle survival

\section{Threats visitors learned about}

Sea turtle rehabilitation centres are beneficial in educating the public about threats to sea turtle survival. As a result of their visit, all visitors indicated that they had learnt about many of the threats sea turtles face, though the specific threats varied by centre (Fig. 1). All visitors at each centre also indicated that they were willing to make at least 1 personal change in their everyday lives to help minimise threats to sea turtles (Fig. 2).

\section{Willingness to pay for sea turtle conservation}

Of the visitors to Reef HQ that were surveyed, 20\% had previously donated money to sea turtle conservation, and, after the tour, an additional 58\% were willing to donate annually to sea turtle conservation. With around 28000 visitors to Reef HQ a year, the tour of the rehabilitation centre could add an economic value of $\$ 131000$ AUD towards sea turtle conservation and \$26800 AUD towards rehabilitation and the facility annually $\underline{1}$ (Table 1 ). Only 1 visitor to

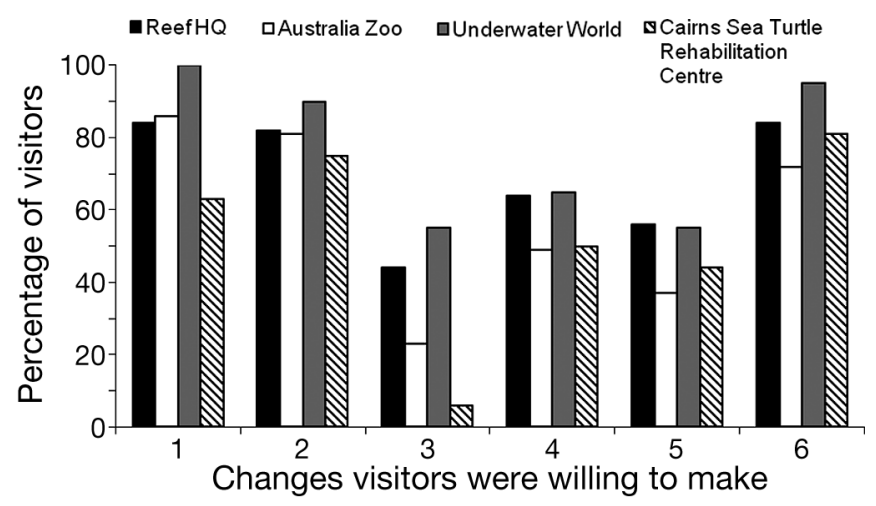

Fig. 2. Survey results: the changes visitors were willing to make in their everyday lives because of their visit to Reef HQ $(\mathrm{N}=136)$, Australia Zoo $(\mathrm{N}=40)$, Underwater World $(\mathrm{N}=20)$, and the Cairns Sea Turtle Rehabilitation Centre $(\mathrm{N}=18) .1$ : dispose of plastics carefully; 2: pick up trash off the beach; 3 : greater care in switching off lights near beaches; 4 : avoid using beaches where sea turtles nest; 5 : operate motor vessels slower in areas with sea turtles; 6 : more likely to report the sighting of sick and injured sea turtles

1Of the visitors surveyed, $78 \%$ are willing to donate as a result of the tour and would donate on average \$6 AUD additionally $(28000 \times 0.78 \times \$ 6 \approx \$ 131000) ; 82 \%$ would pay on average $\$ 0.45$ additionally for a single admission ticket, and $89 \%$ would pay $\$ 0.20$ more for the hospital tour as a result of the tour [ $(28000 \times 0.82 \times \$ 0.45 \approx \$ 21800)+(28000 \times 0.89$ $\times \$ 0.20 \approx \$ 5000)=\$ 26000]$ 
the CSTRC had previously donated money to sea turtle conservation; after the tour, $75 \%$ showed willingness to donate annually to sea turtle conservation. The CSTRC, on average, receives around 1000 visitors each year since it is not open to the public. This facility could add an economic value of \$19500 AUD annually towards sea turtle conservation and \$2000 AUD towards rehabilitation and the facility in general $^{\mathbf{2}}$ (Table 1 ). The added economic value of the rehabilitation centre at Underwater World and Australia Zoo could not be determined because willingness to pay questions could not be asked of visitors at Underwater World and these questions were not asked of visitors at the Australia Zoo before they visited the animal hospital. After the tour of the rehabilitation centre, visitors to Australia Zoo and Underwater World would be willing to donate annually to sea turtle conservation and visitors to the Australia Zoo would be willing to pay more for entrance into the facility and more for the tour (Table 2).

Visitors to the 4 centres varied in their response to where additional payments should go. Overall, after visiting the sea turtle hospital, the majority of visitors to Reef HQ and Underwater World suggested additional payments should go towards rehabilitation, while visitors to the Australia Zoo stated they should go towards education/public awareness, and visitors to the CSTRC recommended they go towards the facility in general (Fig. 3).

Visitors to Reef $\mathrm{HQ}$ that had previously donated money to sea turtle conservation differed significantly in response to visitors that had not previously donated money (Table 3). Previous donors were more likely to strongly agree that sea turtle rehabilitation is valuable for sea turtle conservation (K-W test, $\chi^{2}=6.5$, df $=2, \mathrm{p}<0.05$ ), sea turtle rehabilitation is beneficial for raising public awareness about threats and their management $\left(\mathrm{K}-\mathrm{W}\right.$ test, $\chi^{2}=16.5$, $\mathrm{df}=2, \mathrm{p}<0.001$ ), and sea turtle conservation is very important (K-W test, $\chi^{2}=6.8, \mathrm{df}=2, \mathrm{p}<0.01$ ). Overall, nearly all of the previous donors (94\%) were aware of threats to sea turtle survival, while only $67 \%$ of non-donors were aware $\left(\mathrm{K}-\mathrm{W}\right.$ test, $\chi^{2}=10.1$, $\mathrm{df}=2, \mathrm{p}<0.01)$.
Table 1. Survey results: average amount in Australian dollars (AUD) that visitors to Reef HQ and the Cairns Sea Turtle Rehabilitation Centre would be willing to pay in an annual donation to sea turtle conservation, the additional amount they would pay for a single entrance ticket, and how much they would wing to pay for the rehabilitation centre tour before and after their tour of

\begin{tabular}{lcc}
\hline \multirow{2}{*}{ Willingness to pay } & \multicolumn{2}{c}{ Amount (AUD) } \\
& Before tour & After tour \\
\hline Reef HQ visitors & $37 \pm 32(96)$ & $43 \pm 34(100)$ \\
Annual donation & $3.30 \pm 1.00(81)$ & $3.75 \pm 0.60(95)$ \\
Additional amount for single & & \\
entrance fee & $3.90 \pm 0.90(106)$ & $4.10 \pm 0.30(118)$ \\
Rehabilitation Centre tour & $42 \pm 25(12)$ & $68 \pm 43(15)$ \\
Cairns Sea Turtle Rehabilitation Centre visitors & \\
Annual donation & $9.65 \pm 2.65(14)$ & $11.75 \pm 0.90(15)$ \\
Additional amount for single & & \\
$\quad$ entrance fee \& rehabilitation tour & &
\end{tabular}

Table 2. Survey results: average amount in Australian dollars (AUD) that visinual donation to sea turtle conservation, the additional amount they would pay for a single entrance ticket, and how much they would be willing to pay ehabilitation centre tour after their tour of the hospital. Percentage of isitors willing to pay indicated in brackets. NA: not available

\begin{tabular}{|lcc|}
\hline \multirow{2}{*}{ Willingness to pay } & \multicolumn{2}{c}{ Amount (AUD) } \\
& Australia Zoo & Underwater World \\
\hline Annual donation & $39 \pm 32(24)$ & $47 \pm 41(15)$ \\
$\begin{array}{l}\text { Additional amount for single } \\
\text { entrance fee } \\
\text { Rehabilitation Centre tour }\end{array}$ & $2.20 \pm 0.30(28)$ & NA \\
& $3.70 \pm 1.00(33)$ & NA \\
\hline
\end{tabular}

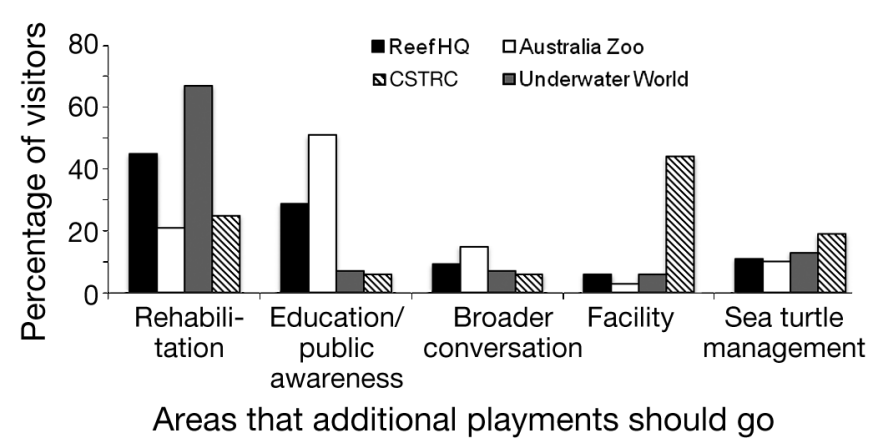

Fig. 3. Survey results: the percentage of visitors to Reef $\mathrm{HQ}$ $(\mathrm{N}=118)$, Australia Zoo $(\mathrm{N}=39)$, Underwater World $(\mathrm{N}=15)$, and the Cairns Sea Turtle Rehabilitation Centre (CSTRC, $\mathrm{N}=16$ ) who suggested that money from additional payments should go towards rehabilitation, education/public awareness, broader conservation initiatives, the facility in general, or for sea turtle management in Queensland

2Of the visitors surveyed, $75 \%$ are willing to donate as a result of the tour and would donate on average \$26 AUD additionally $(1000 \times 0.75 \times \$ 26 \approx \$ 19500) ; 94 \%$ would pay on average $\$ 2.10$ additionally for a single admission including the hospital tour as a result of the tour $(1000 \times 0.94 \times \$ 2.10 \approx$ \$2000) 
Table 3. Survey results: the percentage of visitors to Reef HQ who had previously donated to sea turtle conservation ( $\mathrm{N}=33$ ) and those who had not donated previously $(\mathrm{N}=130)$ who agreed with the following statements

\begin{tabular}{|lccc|}
\hline Statement & \multicolumn{2}{c|}{$\begin{array}{c}\text { Agree (\%) } \\
\text { Strongly agree (\%) } \\
\text { Non-donors }\end{array}$} \\
\hline $\begin{array}{l}\text { Sea turtle rehabilitation is valuable for sea turtle conservation } \\
\text { Sea turtle rehabilitation is beneficial for raising public }\end{array}$ & 47 & 64 & 50 \\
awareness about threats and their management & 13 & 56 & 84 \\
Sea turtle conservation is very important & 22 & 46 & 36 \\
\hline
\end{tabular}

Table 4. Survey results: the percentage of first time visitors $(\mathrm{N}=119)$ and repeat visitors $(\mathrm{N}=47)$ to Reef $\mathrm{HQ}$ who agreed with the following statements

\begin{tabular}{|c|c|c|c|c|}
\hline \multirow[t]{2}{*}{ Statement } & \multicolumn{2}{|c|}{ Agree (\%) } & \multicolumn{2}{|c|}{ Strongly agree (\%) } \\
\hline & First time & Repeat visitors & First time & Repeat visitors \\
\hline Sea turtles are endangered & 53 & 45 & 34 & 53 \\
\hline Rehabilitation helps sea turtle populations increase & 56 & 36 & 40 & 60 \\
\hline Saving sea turtles helps protect the ocean & 50 & 36 & 35 & 53 \\
\hline Sea turtle rehabilitation is valuable for sea turtle conservation & 64 & 51 & 28 & 47 \\
\hline Sea turtle conservation is very important & 48 & 26 & 46 & 74 \\
\hline
\end{tabular}

Table 5. Survey results: the percentage of members $(N=17)$ and non-members $(N=149)$ to Reef HQ who agreed with the following statements

\begin{tabular}{|c|c|c|c|c|}
\hline \multirow[t]{2}{*}{ Statement } & \multicolumn{2}{|c|}{ Agree $(\%)$} & \multicolumn{2}{|c|}{ Strongly agree (\%) } \\
\hline & Members & Non-members & Members & Non-members \\
\hline Saving sea turtles helps protect the ocean & 50 & 36 & 35 & 53 \\
\hline $\begin{array}{l}\text { Sea turtle rehabilitation is beneficial for raising public } \\
\text { awareness about threats and sea turtle management }\end{array}$ & 64 & 51 & 28 & 47 \\
\hline
\end{tabular}

\section{Visitor profile}

The majority of visitors to Reef HQ (73\%) listed the sea turtle hospital, or to see sea turtles specifically, as their primary or secondary reason for visiting. Of the visitors surveyed, $28 \%$ were repeat visitors, $10 \%$ were members of the aquarium, and $14 \%$ had previously visited a sea turtle rehabilitation centre.

First time visitors and repeat visitors to Reef HQ differed significantly in their responses. In particular, repeat visitors were more likely to strongly agree (Table 4 ) that sea turtles are endangered (K-W test, $\chi^{2}=6.8$, $\mathrm{df}=1, \mathrm{p}<0.01$ ), that rehabilitation helps sea turtle population increase $\left(\mathrm{K}-\mathrm{W}\right.$ test, $\chi^{2}=4.8, \mathrm{df}=1, \mathrm{p}<$ $0.05)$, saving sea turtles helps protect the ocean $(\mathrm{K}-\mathrm{W}$ test, $\chi^{2}=4.8, \mathrm{df}=1, \mathrm{p}<0.05$ ), sea turtle rehabilitation is valuable for sea turtle conservation $\left(\mathrm{K}-\mathrm{W}\right.$ test, $\chi^{2}=$ $6.8, \mathrm{df}=1, \mathrm{p}<0.01$ ), and that sea turtle conservation is very important $\left(\mathrm{K}-\mathrm{W}\right.$ test, $\left.\chi^{2}=12.4, \mathrm{df}=1, \mathrm{p}<0.01\right)$. Overall, a majority of both repeat visitors ( $88 \%$ ) and first time visitors $(66 \%)$ were aware of threats to sea turtles, but these percentages were significantly different $\left(\mathrm{K}-\mathrm{W}\right.$ test, $\left.\chi^{2}=11.0, \mathrm{df}=1, \mathrm{p}<0.01\right)$.
Members of Reef HQ (majority are repeat visitors) and non-members differed significantly in their response. Members were more likely to strongly agree (Table 5) that saving sea turtles helps protect the ocean (K-W test, $\left.\chi^{2}=4.3, \mathrm{df}=1, \mathrm{p}<0.05\right)$ and that sea turtle rehabilitation is beneficial for raising public awareness about threats and sea turtle management (K-W test, $\left.\chi^{2}=6.7, \mathrm{df}=1, \mathrm{p}<0.05\right)$. There was also a significant difference in the responses between visitors who had previously visited a sea turtle rehabilitation centre and those who had not (Table 6). Visitors who had previously visited a sea turtle rehabilitation centre were more likely to strongly agree that sea turtle rehabilitation is beneficial for raising public awareness about threats and sea turtle management (K-W test, $\left.\chi^{2}=7.4, \mathrm{df}=1, \mathrm{p}<0.01\right)$. Visitor profile data were only available from Reef $H Q$, because the survey questions could not be given to visitors at Australia Zoo and Underwater World. Visitors to the CSTRC had the same profile because they were a tour group from a local veterinary clinic, and all individuals shared very similar views about sea turtle rehabilitation. 
Table 6. Survey results: the percentage of visitors to Reef HQ who had previously visited a sea turtle rehabilitation centre $(\mathrm{N}=23)$ and visitors who had not $(\mathrm{N}=143)$ who agreed with the following statement

\begin{tabular}{|lccc|}
\hline Statement & \multicolumn{2}{c|}{$\begin{array}{c}\text { Agree (\%) } \\
\text { Repeat visitors }\end{array}$} & $\begin{array}{c}\text { Strongly agree (\%) } \\
\text { First time } \\
\text { Repeat visitors }\end{array}$ \\
\hline $\begin{array}{c}\text { Sea turtle rehabilitation is beneficial for raising public } \\
\text { awareness about threats and sea turtle management }\end{array}$ & 64 & 51 & 28 \\
\hline
\end{tabular}

\section{Visitor demographics}

The visitors to the sea turtle hospital at Reef HQ varied greatly in age, education, employment status, annual income, and primary residence (Fig. 4). Visitors to Reef HQ varied significantly in their responses depending upon income and employment. Individuals earning higher incomes (>\$79 999 AUD) $(\mathrm{N}=32)$ felt more strongly that sea turtle rehabilitation is beneficial for raising public awareness about threats and their management $\left(\mathrm{K}-\mathrm{W}\right.$ test, $\chi^{2}=21.8$, $\mathrm{df}=8, \mathrm{p}<0.01$ ), were willing to pay more for a single entrance fee (K-W test, $\left.\chi^{2}=18.7, \mathrm{df}=8, \mathrm{p}<0.05\right)$, and more for the hospital tour (K-W test, $\chi^{2}=17.6, \mathrm{df}=8$, $\mathrm{p}<0.05)$ than visitors with an annual income under $\$ 80000$ AUD ( $\mathrm{N}=107)$. Additionally, visitors who were employed full- or part-time $(\mathrm{N}=67)$ were willing to pay more for sea turtle conservation (K-W test, $\chi^{2}=30.3, \mathrm{df}=7, \mathrm{p}<0.01$ ), and also felt more strongly that sea turtle rehabilitation is beneficial for raising public awareness about threats and their management ( $\mathrm{K}-\mathrm{W}$ test, $\chi^{2}=18.6, \mathrm{df}=7, \mathrm{p}<0.01$ ) than visitors who were self-employed, students, retired, homemakers, or not employed $(\mathrm{N}=58)$. However, there was no statistically significant difference between responses from visitors of different age groups, gender, or education.

Visitors from different states in Australia and different countries differed significantly in their response. More visitors from coastal Queensland $(32 \%)$ had previously donated to sea turtle conservation compared with visitors from other regions

Table 7. Survey results: amount in Australian dollars that visitors from coastal Queensland $(\mathrm{N}=61)$ and other regions $(\mathrm{N}=58)$ (inland Queensland, the rest of Australia, New Zealand, and Europe) would be willing to contribute as an annual donation to sea turtle conservation

\begin{tabular}{|lccc|}
\hline \multirow{2}{*}{ Visitors from } & \multicolumn{3}{c|}{ Visitors willing to pay (\%) } \\
& $<\$ 50$ & $\$ 50-99$ & $\$ 100-149$ \\
\hline Coastal Queensland & 80 & 15 & 5 \\
Other regions & 83 & 12 & 5 \\
\hline
\end{tabular}

$(10 \%)\left(\mathrm{K}-\mathrm{W}\right.$ test, $\left.\chi^{2}=16.2, \mathrm{df}=5, \mathrm{p}<0.01\right)$; however, there was no significant difference in how much visitors would be willing to contribute as an annual donation towards sea turtle conservation (Table 7; K-W test, $\chi^{2}=1.4, \mathrm{df}=5, \mathrm{p}=0.91$ ). There was a significant difference between Queensland residents and visitors from the rest of Australia, Europe, or New Zealand in how much they would be willing to pay additionally for a single entrance fee $\left(\mathrm{K}-\mathrm{W}\right.$ test, $\chi^{2}=16.2$, df $\left.=5, \mathrm{p}<0.05\right)$ and how much they would be willing to pay for the hospital tour at Reef HQ (K-W test, $\chi^{2}=11.4$, df $=5, \mathrm{p}<$ 0.05). Overall, visitors from both coastal and inland Queensland would pay more for a single entrance fee (Table 8A) and more for the tour of the rehabilitation centre (Table 8B).

Visitors from Australia and New Zealand agreed more strongly that sea turtle rehabilitation is valuable for sea turtle conservation (K-W test, $\chi^{2}=19.8$, $\mathrm{df}=5, \mathrm{p}<0.01)$ and that sea turtle conservation is very important ( $\mathrm{K}-\mathrm{W}$ test, $\chi^{2}=21.6, \mathrm{df}=5, \mathrm{p}<0.001$ ), compared with visitors from Europe (Table 9). Additionally, Queensland residents strongly agreed that sea turtle rehabilitation is beneficial for raising public awareness about threats and their management

Table 8. Survey results. (A) Additional amount in Australian dollars that visitors from Queensland $(\mathrm{N}=89)$, the rest of Australia, New Zealand, and Europe $(\mathrm{N}=67)$ would be willing to pay for a single entrance ticket to Reef HQ. (B) The amount that visitors from Queensland $(\mathrm{N}=89)$, the rest of Australia, New Zealand, and Europe ( $\mathrm{N}=67$ ) would be willing to pay for the tour of the sea turtle rehabilitation centre at Reef $\mathrm{HQ}$

Visitors from Visitors willing to pay (\%) $\$ 0 \quad \$ 1-3 \quad \$ 4-6 \quad \$ 7-9>\$ 10$

(A)

Queensland

Rest of Australia, $\begin{array}{lllll}21 & 27 & 28 & 8 & 16\end{array}$

New Zealand, \& Europe (B)

Queensland

Rest of Australia,

New Zealand, \& Europe 

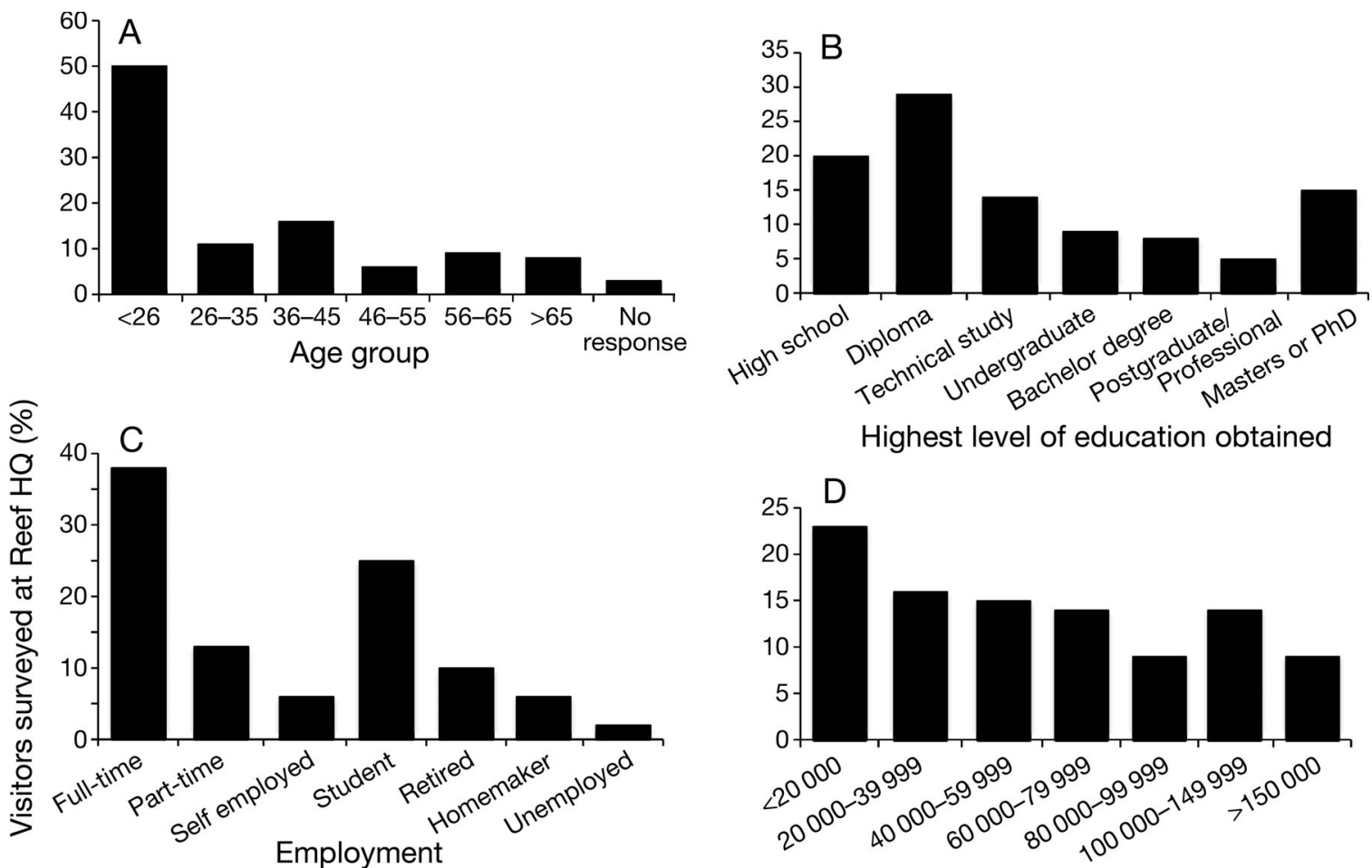

Highest level of education obtained

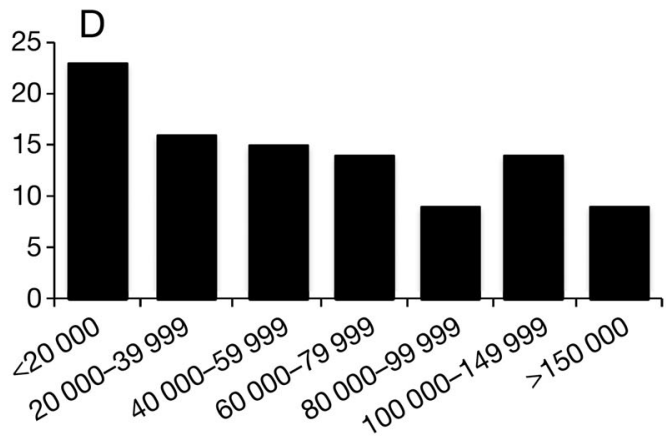

Annual household income (AUD) before taxes in 2010

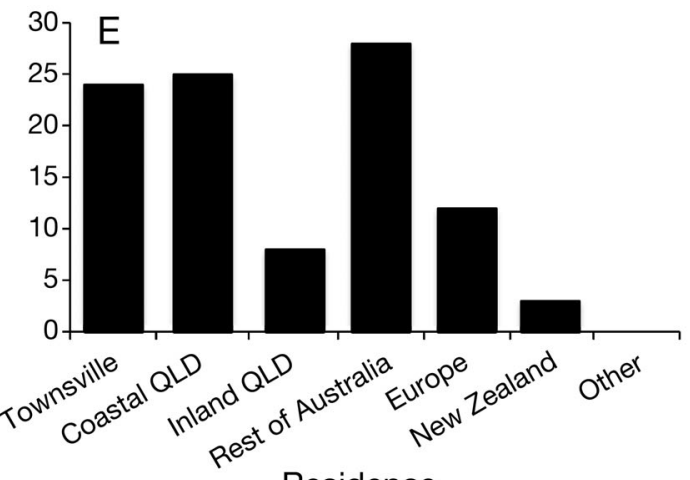

Fig. 4. Socio-economic data of surveyed visitors to Reef $\mathrm{HQ}$ ( $\mathrm{N}=119$ ). (A) Age range of visitors. (B) Highest level of education obtained by visitors. (C) Employment status of visitors. (D) Annual household income (AUD: Australian dollars) before taxes in 2010. (E) Visitors' permanent residence (inland

Residence

Queensland [QLD] is considered $>50 \mathrm{~km}$ from the coast)

Table 9. Survey results: the percentage of visitors to Reef HQ whose primary residence is in Australia or New Zealand (Aus \& $\mathrm{NZ}, \mathrm{N}=138$ ) and visitors whose primary residence is in Europe $(\mathrm{N}=18)$ who agreed with the following statement

\begin{tabular}{|c|c|c|c|c|}
\hline \multirow[t]{2}{*}{ Statement } & \multicolumn{2}{|c|}{ Agree $(\%)$} & \multicolumn{2}{|c|}{ Strongly agree (\%) } \\
\hline & Aus \& NZ & Europe & Aus \& NZ & Europe \\
\hline Sea turtle rehabilitation is valuable for sea turtle conservation & 62 & 59 & 36 & 12 \\
\hline Sea turtle conservation is very important & 40 & 56 & 58 & 22 \\
\hline
\end{tabular}

Table 10. Survey results: the percentage of visitors to Reef HQ whose primary residence is in Queensland $(\mathrm{N}=89)$ and other regions $(\mathrm{N}=62)$ (the rest of Australia, New Zealand, or Europe) who agreed with the following statement

\begin{tabular}{|c|c|c|c|c|}
\hline \multirow[t]{2}{*}{ Statement } & \multicolumn{2}{|c|}{ Agree (\%) } & \multicolumn{2}{|c|}{ Strongly agree (\%) } \\
\hline & Queensland & Other regions & Queensland & Other regions \\
\hline $\begin{array}{l}\text { Sea turtle rehabilitation is beneficial for raising public } \\
\text { awareness about threats and their management }\end{array}$ & 38 & 63 & 58 & 24 \\
\hline
\end{tabular}


$\left(\mathrm{K}-\mathrm{W}\right.$ test, $\left.\chi^{2}=32.8, \mathrm{df}=5, \mathrm{p}<0.001\right)$ compared with visitors from the rest of Australia, New Zealand, and Europe (Table 10). Overall, visitors from Queensland $(82 \%)$ were more aware of threats to sea turtle survival than visitors from the rest of Australia (64\%) (KW test, $\chi^{2}=21.3$, df $\left.=5, \mathrm{p}<0.001\right)$. Visitor demographic data were only available from Reef $\mathrm{HQ}$ because it was not possible to survey visitors at the Australia Zoo and Underwater World. Visitors to the CSTRC were all around the same age, had the same level of education, employment status, annual income, and primary residence; therefore, there was no comparison to be made.

\section{DISCUSSION}

Sea turtle rehabilitation centres operate worldwide and can be a valuable tool for conservation by educating visitors about threats to sea turtles, especially ones due to human actions and how visitors' everyday actions can, both positively and negatively, impact sea turtles and the environment in general. However, these indirect values remain, for the most part, unquantified. We examined whether visitors to sea turtle rehabilitation centres are more likely to adopt a behavioural change in their lives to help protect sea turtles and/or donate money to sea turtle conservation, and our study demonstrated that rehabilitation centres could have a significant conservation role through education and awareness.

\section{Threats visitors learned about}

Visitors varied between centres in what they considered were the main threats to sea turtle survival. This was found to be dependent on the turtles currently in care at the facilities and the main conservation message each facility presented. Sea turtles are impacted by many different threats along the Australian coast. In northern Queensland, seagrass beds were severely impacted by Cyclone Yasi, which caused extensive flooding over much of Queensland in February 2011. As a result of this, many of the sea turtles coming into the CSTRC and Reef HQ during 2011 were in poor body condition arising from lack of food sources. Additionally, the CSTRC has the facilities to take in cases of fibropapillomatosis. Reef HQ, Underwater world, and Australia Zoo cannot take these turtles; therefore, visitors to CSTRC learned more about diseases, specifically fibropapillomatosis, than visitors to the other facilities.
Throughout Queensland, one main threat to sea turtles is gut impaction, which is often caused by the ingestion of marine debris, pneumonia, disease, or parasite overload. Currently, this threat is discussed more than other threats at all 4 facilities surveyed. Boat strikes and bycatch in fisheries affect a large number of sea turtles in Queensland; however, these threats were not considered as serious by visitors as other threats, such as loss of nesting habitat, coastal development, and climate change, and were not discussed as frequently.

Studies have shown that wildlife encounters can lead to enhanced educational and conservation outcomes for visitors (Zeppel 2008). Benefits include increased understanding or emotional response to marine wildlife encounters, which may lead to greater environmental awareness, support for marine conservation, and protection of endangered species (Wilson \& Tisdell 2003, Ballantyne et al. 2009, Ballantyne \& Packer 2011). Conservation benefits gained from wildlife tourism include financial support for conservation and education of visitors, which may lead to more conservation-focused behaviour and support (Higginbottom \& Tribe 2004, Zeppel 2008). After learning about threats to sea turtles, our study demonstrated that all visitors were willing to make a change in their lives to help minimise threats to sea turtle survival. Ballantyne et al. (2009) found that many wildlife tourism visitors already participated in conservation actions that require a low level of commitment, such as recycling or conserving water and energy.

In order to change the daily behaviour of visitors, education has been shown to be important, demonstrating that visitors can participate in events locally that will influence conservation issues (Ballantyne \& Packer 2005, Ballantyne et al. 2007a, 2011, Zeppel 2008). In our study, visitors surveyed at Reef HQ learned about what they could do to make a difference in the protection of sea turtles. This included not using plastic bags/greater care in disposing of plastics, picking up trash, and reporting sick or injured sea turtles. After the tour, almost all visitors to Reef HQ stated that they would be more likely to make the previous changes in their lives following their visit. Ballantyne et al. (2011) found that examples offered of how visitors' everyday actions can, both positively and negatively, impact sea turtles and practical and achievable things that individuals can do to contribute to sea turtle conservation provided a stronger conservation message that visitors would remember when they returned home. 


\section{Willingness to pay for sea turtle conservation}

More visitors to Reef $H Q$, Underwater World, and the CSTRC said they would be willing to donate annually to sea turtle conservation than visitors to Australia Zoo. Reasons for this could be that visitors at Australia Zoo did not see the turtles that were in the rehabilitation centre. Additionally, visitors to the wildlife hospital do not receive any interactive presentations; turtle conservation information was limited to posters in one corner of the facility, describing some of the threats that sea turtles face. Furthermore, staff or volunteers were not available to answer the questions visitors may have had about sea turtle rehabilitation, which has been shown by other studies (Ballantyne \& Packer 2011) to help promote a stronger conservation message. Previous studies have also shown that zoo visitors who have been exposed to wildlife along with some interpretation are more supportive of wildlife conservation in general as well as of conservation of target species such as sea turtles (Moscardo et al. 2001, Tribe \& Booth 2003). The majority of zoo visitors also learn more from interactive presentations than stationary displays (Tribe \& Booth 2003). Therefore, rehabilitation centres that include an interactive presentation will be more successful in educating visitors about the threats to sea turtles as well as in delivering a stronger conservation message leading to increased financial support for sea turtle conservation.

Additionally, personal encounters with marine wildlife along with educational programs are more likely to generate conservation appreciation and action by visitors (Ballantyne et al. 2007b). Comparisons of visitors at all 4 facilities demonstrated they were willing to donate similar amounts towards sea turtle conservation. This is most likely because the average amount people stated they would be willing to donate was low overall $\left(<\$ 50 \mathrm{AUD} \mathrm{yr}^{-1}\right)$ and mostly likely affordable to the majority of visitors; however, whether visitors actually donate to sea turtle conservation after their visit is unknown and quantification would need a longer term follow-up study.

Rehabilitation can take a long time, and it is expensive to feed and treat the animals when in the facilities. A total of 121731 people visited Reef HQ in person; of these, 23900 visitors toured the turtle hospital, which cared for 57 turtles, with 20 being released between 2010 and 2011 (GBRMPA 2011). The total revenue was $\$ 2.8$ million AUD for the year, which barely covers the cost of running the facility (GBRMPA 2011). Additionally, Reef HQ is run by the Great Barrier Reef Marine Park Authority (GBRMPA), which uses some of the revenue to support other conservation programs (GBRMPA 2011). Therefore, it is important that the centre has a strong and consistent conservation message, which raises awareness of the Great Barrier Reef's value and the threats it faces, including those to sea turtles. Revenue for Australia Zoo, Underwater World, and the CSTRC are unknown. Australia Zoo, however, operates many other terrestrial and marine conservation programs, and much of their revenue goes to the facility and to indigenous species conservation. Underwater World also operates a large facility with conservation programs other than their rehabilitation centre.

Higher numbers of visitors to Reef $\mathrm{HQ}$ and the CSTRC said they would be willing to pay more for a single entrance fee into the facility than visitors to Australia Zoo; the same was true of paying more on average towards rehabilitation and the facility. However, around the same percentage of visitors to the Australia Zoo would pay more for admission into the wildlife hospital, though visitors to Reef $\mathrm{HQ}$ and the CSTRC would pay more on average. This additional revenue could benefit conservation to address the threats that sea turtles face and towards further research into mitigating these threats (Wilson \& Tisdell 2000). The economic value of sea turtles as a tourist draw could also be used as an argument providing economic incentives to communities that depend on turtles (Wilson \& Tisdell 2000), which could help turtle populations recover. Turtles' economic value can also lead towards legal support to minimise threats such as enforcing 'go slow zones' (Wilson \& Tisdell 2000).

After the tour, more visitors to Reef HQ suggested that additional payments should go towards rehabilitation and education/public awareness, and less money should go toward broader conservation, the facility, or sea turtle management in Queensland. Visitors to the CSTRC suggested that more money should go towards the facility and sea turtle management in Queensland and less should go towards rehabilitation and education/public awareness after the tour. The majority of visitors to the Australia Zoo suggested that donations should go towards education/public awareness, while the majority of visitors to Underwater World felt that money should go towards rehabilitating individual turtles rather than towards broader conservation goals or the management of sea turtles in general. Hence, visitors may falsely believe that rehabilitation alone is sufficient to protect sea turtles and that additional funds should go towards other areas unrelated to sea turtle conservation. It is important that these facilities educate vis- 
itors that rehabilitation alone will not help sea turtle populations recover and that it will require a change in people's behaviour to help manage threats to aid in sea turtle conservation.

Both Reef HQ and Underwater World are public aquariums, and money from admission goes towards many different animals and their care. Therefore, guests would prefer that donations go towards s ea turtle rehabilitation specifically rather than other species at the facilities. At the Australia Zoo, visitors do not learn anything about sea turtle rehabilitation, only about threats and conservation. Therefore, it would be beneficial if more money were allocated to educating the public about threats, since very little information is provided. Lastly, the CSTRC is solely a sea turtle rehabilitation centre, and visitors suggest that money should go towards the facility, which ultimately goes towards rehabilitation. More money to the facility could mean that the facility could expand and potentially take in more injured sea turtles and educate more visitors.

\section{Visitor profile and demographics}

Overall, repeat visitors, aquarium members, and previous visitors of sea turtle rehabilitation centres to Reef HQ tended to feel stronger about the importance of sea turtle conservation. The reason for this outcome could be attributed to the fact that visitors who have previously visited conservation-themed facilities are likely to have more knowledge about conservation issues than the general public (Falk \& Adelman 2003, Ballantyne et al. 2007b, 2009). In addition, visitors with a higher income were willing to pay a higher entrance fee and more for the hospital tour and felt more strongly that sea turtle rehabilitation is beneficial for raising public awareness about the threats and their management. This was expected and found in other studies (Tisdell \& Wilson 2002b), because higher income individuals are often willing to donate more towards conservation and rehabilitation than individuals with lower incomes (Tisdell \& Wilson 2001).

Overall, visitors from both coastal and inland Queensland felt more strongly about the importance of sea turtle rehabilitation than visitors from other regions of Australia, Europe, or New Zealand. Sea turtles are found worldwide; however, in Australia, their nesting grounds are in the northern tropical regions (Tisdell \& Wilson 2001, 2002b). Due to their complex life cycles, most people only have the opportunity to observe sea turtles in the wild at nesting beaches or by scuba diving. Therefore, residents of Queensland, of which the Great Barrier Reef catchments are approximately $20 \%$ of the state's area, may have had a previous opportunity to view sea turtles and, consequently, may feel more strongly about protecting them and donating money towards sea turtle conservation.

\section{CONCLUSIONS}

In general, visitors to Reef HQ, Underwater World, Australia Zoo, and the CSTRC learned about the threats to sea turtle survival, were willing to make a change in their lives to help minimise threats, and were more willing to donate money towards sea turtle conservation. The sample, however, may not have been an accurate representation of all visitors who come to facilities that have a sea turtle hospital. Visitors that were willing to be surveyed and visitors that arrived early for the tour of Reef HQ may be more conservation minded or care more about sea turtle health than visitors who were not surveyed. Therefore, it is important that rehabilitation centres have a strong educational component, since the conservation value of the rehabilitation centre is essentially its role as an education provider. Also, a strong educational aspect is needed in other areas of the facility to reach visitors who do not visit the sea turtle rehabilitation area. Rehabilitation alone will not help sea turtle populations recover unless anthropogenic threats to their survival are minimised. In order for this to occur, the public needs to be informed about the threats and how they can make a difference in their own lives. Ballantyne et al. (2011) found that information given to visitors about threats to the animals was better retained than 'scientific' information (e.g. turtle biology/ecology/distribution/evolution).

It is important that rehabilitation centres have a strong and consistent (at least within a centre) conservation message. More emphasis should be placed on spending adequate money on designing the best educational message about sea turtle conservation, including educating visitors about all the threats that affect sea turtles, as well as how they can help protect sea turtles in their everyday lives. Without a strong educational component, the conservation value of the rehabilitation centre is minimised.

In addition, visitors will most likely not be as receptive to the conservation message at centres such as the Australia Zoo, where sea turtles are not visible, and facilities such as Sea World, where the rehabilitation centre is not available for the public to ob- 
serve. Ballantyne et al. (2009) found that experiences which offer encounters with wildlife along with a conservation message can enhance visitors' learning and influence their long-term behaviour. Furthermore, the economic value of sea turtle rehabilitation centres can go towards minimising threats to survival and sea turtle conservation in general. Further studies are needed in order determine the educational value of other sea turtle rehabilitation centres, as well as to make comparisons between the public's knowledge and that of rehabilitation centre volunteers. Also follow-up studies should be conducted after visitors have returned home to determine whether they actually donated to sea turtle conservation and/or made a change in their everyday lives to help minimise threats to sea turtles. Follow-up surveys of visitors to Mon Repos Conservation Park found that visitors had already made a change in their everyday behaviours, such as not using plastic bags, being more careful with rubbish disposal, and picking up trash, as a result of their visit (Ballantyne et al. 2011).

Acknowledgements. This work was carried out under the human research ethics permit, Number H4309. Thanks to Natalie Stoeckl for providing valuable comments on the survey design, and 4 anonymous reviewers for their constructive comments. This research would not have been possible without the assistance of the staff at Reef $\mathrm{HQ}_{\text {, Underwater }}$ World, and the Australia Zoo, and the help of Jennifer Gilbert at the Cairns Sea Turtle Rehabilitation Centre.

\section{LITERATURE CITED}

Ballantyne R, Packer J (2005) Promoting environmentally sustainable attitudes and behaviour through free-choice learning experiences: What is the state of the game? Environ Educ Res 11:281-295

Ballantyne R, Packer J, Bond N (2007a) The impact of a wildlife tourism experience on visitors' conservation knowledge, attitudes and behaviour: preliminary results from Mon Repos turtle rookery, Queensland. In: McDonnell I, Grabowski S, March R (eds) Proceedings of the CAUTHE Conference on tourism - past achievements, future challenges. University of Technology, Sydney

Ballantyne R, Packer J, Hughes K, Dierking L (2007b) Conservation learning in wildlife tourism settings: lessons from research in zoos and aquariums. Environ Educ Res 13:367-383

Ballantyne R, Packer J, Hughes K (2009) Tourists' support for conservation messages and sustainable management practices in wildlife tourism experiences. Tour Manag 30:658-664

Ballantyne R, Packer J (2011) Using tourism free-choice learning experiences to promote environmentally sustainable behaviour: the role of post-visit 'action resources'. Environ Educ Res 17:201-215

Ballantyne R, Packer J, Sutherland L (2011) Visitors' memories of wildlife tourism: implications for the design of powerful interpretive experiences. Tour Manage 32: 770-779

Campbell LM, Smith C (2005) Volunteering for sea turtles? Characteristics and motives of volunteers working with the Caribbean conservation corporation in Tortuguero, Costa Rica. Marit Stud 3:169-193

Campbell LM, Smith C (2006) What makes them pay? Values of volunteer tourists working for sea turtle conservation. Environ Manag 38:84-98

Cardona L, Fernandez G, Revelles M, Aguilar A (2012) Readaptation to the wild of rehabilitated loggerhead sea turtles (Caretta caretta) assessed by satellite telemetry. Aquat Conserv Mar Freshw Ecosyst 22:104-112

Casale P, Affronte M, Insacco G, Freggi D and others (2010) Sea turtle strandings reveal high anthropogenic mortality in Italian waters. Aquat Conserv Mar Freshw Ecosyst 20:611-620

Chaloupka M, Limpus C (2001) Trends in the abundance of sea turtles resident in southern Great Barrier Reef waters. Biol Conserv 102:235-249

SEQPaC (Dept of Sustainability, Environment, Water, Population and Communities) (2003) Recovery plan for marine turtles in Australia. Canberra, ACT, p 1-49

Falk J, Adelman L (2003) Investigating the impact of prior knowledge and interest on aquarium visitor learning. J Res Sci Teach 40:163-176

> Gray N, Campbell L (2007) A decommodified experience? Exploring aesthetic, economic and ethical values for volunteer ecotourism in Costa Rica. J Sustainable Tourism 15:463-482

GBRMPA (Great Barrier Reef Marine Park Authority) (2011) Great Barrier Reef marine park authority annual report 2010-11. GBRMPA, Townsville, QLD

Greenland J, Limpus C (2003) Marine wildlife stranding and mortality database annual report 2003. III. Marine turtles. Conserv Tech Data Rep, Vol 2003, No. 3. Queensland Government (www.epa.qld.gov.au)

> Hazel J, Lawler I, Marsh H, Robson S (2007) Vessel speed increases collision risk for the green turtle Chelonia mydas. Endang Species Res 3:105-113

Higginbottom K, Tribe A (2004) Contributions of wildlife tourism to conservation. In: Higginbottom K (ed) Wildlife tourism: impacts, management and planning. Common Ground Publishing, Altona, VIC p 99-123

> Hutchinson J, Simmonds M (1992) Escalation of threats to marine turtles. Oryx 26:95-103

Meredith A, Keeble E (2011) Wildlife medicine and rehabilitation. Manson Publishing, London

Moscardo G, Woods B, Greenwood T (2001) Understanding visitor perspectives on wildlife tourism. Status assessment of wildlife tourism in Australia Series. Wildlife Tourism Report Series No. 2, CRC for Sustainable Tourism, Gold Coast

Mrosovsky N, Ryan G, James M (2009) Leatherback turtles: the menace of plastic. Mar Pollut Bull 58:287-289

Tisdell C, Wilson C (2001) Wildlife-based tourism and increased support for nature conservation financially and otherwise: evidence from sea turtle ecotourism at Mon Repos. Tourism Econ 7:233-249

Tisdell C, Wilson C (2002a) Economic educational and conservation benefits of sea turtle based ecotourism: a study focused on Mon Repos. Wildlife Tourism Report Series No. 20, CRC for Sustainable Tourism, Gold Coast

Tisdell C, Wilson C (2002b) Ecotourism for the survival of sea turtles and other wildlife. Biodivers Conserv 11:1521-1538 
Tisdell C, Wilson C (2003) Does ecotourism contribute to sea turtle conservation? Is the flagship status of turtles advantageous? Economics, ecology and the environment. Working Paper No. 90, School of Economics, The University of Queensland, Brisbane, QLD

Tisdell C, Wilson C (2005a) Does tourism contribute to sea turtle conservation? Is the flagship status of turtles advantageous? Marit Stud 3:145-167

Tisdell C, Wilson C (2005b) Perceived impacts of ecotourism on environmental learning and conservation: turtle watching as a case study. Environ Dev Sustain 7:291-302

Tribe A, Booth R (2003) Assessing the role of zoos in wildlife conservation. Hum Dimens Wildl 8:65-74

Wallace BP, Lewison RL, McDonald SL, McDonald RK and

Editorial responsibility: Clement Tisdell,

Brisbane, Queensland, Australia others (2010) Global patterns of marine turtle bycatch. Conserv Lett 3:131-142

Wallace BP, DiMatteo A, Bolten A, Chaloupka M and others (2011) Global conservation priorities for marine turtles. PLoS ONE 6:e24510

Wilson C, Tisdell C (2000) Sea turtles as a non-consumptive tourism resource especially in Australia. Econ Issues (Brisbane) 11:1-29

Wilson C, Tisdell C (2003) Conservation and economic benefits of wildlife-based marine tourism: sea turtles and whales as case studies. Hum Dimens Wildl 8:49-58

Zeppel H (2008) Education and conservation benefits of marine wildlife tours: developing free-choice learning experiences. J Environ Educ 39:3-18

Submitted: February 1, 2012; Accepted: November 26, 2012 Proofs received from author(s): March 27, 2013 